\title{
Training of Civil Engineers for Work in Design Team
}

\author{
Elena Romanova ${ }^{1, *}$ \\ ${ }^{1}$ Moscow State University of Civil Engineering, Yaroslavskoe shosse, 26, Moscow, 129337, Russia
}

\begin{abstract}
Creation technically of difficult construction projects is impossible alone. Project teams from among the certified specialists with a work experience are for this purpose formed. In Russia the civil engineer doesn't need the certificate. But without work experience of the young specialist don't take in a project team. It is possible to gain experience of team work during training in the program of a magistracy. In article experience of implementation in the Moscow State University of Civil Engineering of special discipline "Social, psychological and legal communications" is described. Content of a theoretical part and the organization of work on a practical training is stated. It is shown how the educational program helps students to purchase the social competences necessary for team work.
\end{abstract}

\section{Introduction}

The habitat of people becomes more difficult every year. In space of the cities there are ambitious construction projects, for example Moscow City in Moscow, Tokyo Skytree, an entertainment complex of Lotte World in Seoul, Agora Garden in Taipai, Songjiang hotel in Shanghai and others. It is impossible to create and realize such project alone. Only the team of people with various skills can cope with a similar task. The civil engineer in this process plays a key role. The competent civil engineers create architecture and infrastructure which in the best way conforms to unique requirements of the environment $[1,2]$. They are capable to combine creatively different approaches and the points of view, to understand life cycle of infrastructure of the building, to solve technical problems [3]. For this purpose specialists builders have to understand accurately mathematics and natural sciences, and also have many other skills: critical and analytical thinking, management of time, management of people and good communicative skills [4]. They must have knowledge in sociology and anthropology, to be able to connect in creative process local traditions with technocratic and bureaucratic knowledge $[5,6]$.

Construction of the new building, quarter or smart city is the difficult project technically. For its implementation the project team is formed. It consists of specialists with various professional skills. Each specialist has the opinion concerning the project, the style and a method of its accomplishment. Uniqueness and autonomy of people interferes them with joint operation. Coordination of actions is necessary for work on the project. Common

*Corresponding author: romanova_e_v@mail.ru 
goals and an order, obligatory for all, high professional qualification, cooperation, trust and loyalty of team members creates conditions for emergence of successful team. Such team has the synergy potential and the highest efficiency. It is obvious that work in such team demands from participants of special social skills. These social skills need to be created specially during training of civil engineers $[7,8]$.

There is a paradox. On the one hand, the professional community requires that graduates of universities owned, first of all, special professional skills [9]. And universities strengthen professional training. On the other hand, employers complain of lack of communicative skills and a work experience in a project team [10]. And on forming of these abilities it is necessary to take school hours somewhere. Students are also dissatisfied with quality of the education worldwide [11, 12]. Programs of training of civil engineers join special training courses. They overcome the contradiction called above and purposefully create social competences. At the Russian universities they are also developed, separately for training of bachelors and masters $[13,14,15]$.

\section{Tasks and results}

In an experimental part of a research methods of the analysis of regulating documents and the reflexive analysis, a method of the creating experiment are used.

The educational program of masters for the Construction in Russia made complies with the Federal State Education Standard of the Higher Education. It have 120 units. A half of this volume makes theoretical training, and a half of volume - internship.

In the theoretical unit $1 / 3$ of units occupy so-called basic disciplines. They create common cultural and all-professional competences, lay the foundation of professional competences. Here enter:

Philosophical problems of science and technology

Social, psychological, legal communications

Business foreign language

Applied mathematics

Bases of scientific research

Bases of professional activity

Further these professional competences develop in disciplines of a variable part. It reflects specifics of the selected sphere of future activities and professional interests. Now Council on professional qualifications in construction on the base of National union of construction engineers solves a problem of development of 107 professional standards in the construction sphere. Soon each university will independently select professional competences according to the selected professional standard. The ratio of different parts of the educational program is provided in fig. 1.

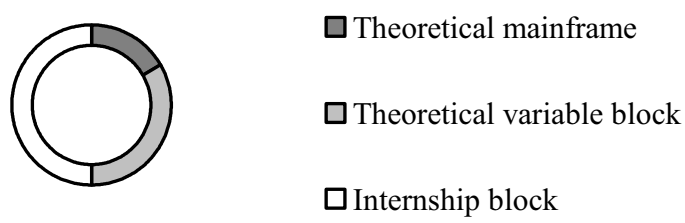

Fig. 1. Contents of the educational program of magistracy in the direction of preparation Construction

The professional environment and Federal State Education Standard in the Construction direction require that specialists in the field of a construction showed such social qualities (competences): 
readiness to bear social and ethical responsibility for the made decisions; readiness for self-development, self-realization, use of creative potential;

readiness to show skills of work in research team, to direct collective in the sphere of the professional activity, tolerantly perceiving social, ethnic, confessional and cultural distinctions;

the capability to influence forming of the purposes of team, to influence its social and psychological climate, to show active social mobility;

capability to use profound knowledge of legal and ethical standards in case of assessment of consequences of the professional activity, in case of development and implementation of socially important projects.

The problem of this research consisted in development of the training program which will help future civil engineers to be prepared for work in design team and to create the social competences stated above. For the solution of this task in Moscow State University of Civil Engineering the discipline "Social, Psychological and Legal Communications" has been created.

Difficulty of development of a course consisted in deduction of social aspect of work in design team. This discipline doesn't set as the purpose to open and describe all stages of work on the project. Studying this small course, students learn to understand psychological and social features of collaboration, to overcome difficulties of interaction, develop tolerance to other cultures, gain experience of collaboration over social projects. Authors of a course understand that after completion of training the student has no skill of work in design team. He only shows readiness for such work.

The academic discipline "Social, Psychological and Legal communications" includes traditional forms of work: lectures, practical training, independent work and control. Labor input of discipline makes only 3 units. Classroom occupations occupy $25 \%$.

The lecture rate states the following subjects:

Values of professional community of builders

Role of the international, professional, corporate standards and standards in professional collective

The principles of the organization of work in collective in the sphere of professional activity

These subjects create an active social position, understanding of complexity of the professional circle of builders and the legal basis of implementation of the international projects.

Work in a project team, especially in the international team is a work with different people, with their different personal features. There are a lot of differences between cultures in one country and between some countries, and all of them are difficult. Civil engineers should accept these distinctions and treat them, as reality. For the best understanding of psychological and social distinctions of different workers and different cultures the training course provides studying of such subjects:

Interpersonal and intergroup interactions in the professional sphere.

Personal and professional relations.

Features of manifestation of cross-cultural distinctions in work of collective.

Creativity as individual activities.

Creativity and collective activities.

Team work.

Decision making in standard and unusual situations.

The lecture rate provides theoretical preparation, creates a value system and outlooks. Students can put the gained knowledge into practice during the trainings, role and business games, discussions, in case of the solution of cases [16]. 
On the first practical training students learn to set correctly such purposes of joint operation which consider interests of all parties. They train to approve the actions during the work at first in couples, then in the three. At the first stage it is very difficult to execute it. Many students have high leader potential and don't want to submit to other participants and the set rules. Gradually actions of members of group become more approved. The quantity of conflict situations decreases, overall performance increases.

At this time it is possible to unite several mini-groups in one team. As students already have experience of group work, understand processes of a group dynamics and cultural distinctions, the stage of coordination of roles and distribution of obligations passes in big team quicker. On final occupations students develop the construction project of the high rise building, prove its cost efficiency and feasibility. This task is control. It shows the gained work experience in team, overcoming communication barriers, correctness of the made decisions and creates social responsibility. This business game helps students to see the work from outside and to receive feedback. Work on the project is divided into four stages. At the first stage students unite in teams and receive a task: to construct a tower in the set parameters (beautiful, steady, and economic). At the second stage students create the project of a tower on paper and technology of its creation. At the third stage of team exchange projects and builds a tower according to the drawing and technology of other team. At the fourth stage of team estimate work of each other, describe merits and demerits, give feedback.

During independent work students study additional theoretical material, carry out selfdiagnostics and a reflection of the psychological features, analyze specific situations. Independent work is generally organized in the form of interactive training. Interactivity of training is implemented at two levels: at the level of interaction of students among themselves, and at the level of their interaction with electronic tutorials. An interactive acceptance of training in independent activities allows solving directly several problems: develop communicative skills, help establishment of emotional contacts between participants of process, force to work in team, to listen to opinion of everyone. Students carry out the most part of work in mini-groups. It allows transferring knowledge and abilities gained on occupation to real practical activities.

Control tasks are also performed in groups. Control of practical skills is described above. Control of theoretical knowledge can be carried out in the form of the group answer to questions. The group receives one volume of test questions and hands over one set of answers. The result can be summed up and as an arithmetic average of individual answers of all students of group. In this case the rating place of group depends on a contribution of each of participants. Only the group form of control allows estimating adequately formation of required social competences, readiness for social interaction and joint operation over a common goal.

\section{Conclusions}

Employers in the construction sphere consider that graduates of construction organizations are insufficiently ready to carry out job responsibilities of the specialist on high skill level [13]. The experience got in educational audiences is insufficient for implementation of difficult projects. Requirements of the professional standard to heads of project teams assume experience of practical work in this or that specialty in the sphere of a construction at least 3 years. In many countries, for example Great Britain, Australia, Canada, construction engineers also shall get sufficient experience and knowledge before beginning independent professional activity. They can form the project team and bear responsibility for the developed and built constructions and buildings, having only received the appropriate certificate. 
Specialized training courses and a large number of case studies, trainings, business games and other kinds of activity in educational programs are the first and very important stage of training of civil engineers which is directed to obtaining necessary abilities for work in design team.

The analysis of the curriculum of masters in the Construction direction shows that in the Russian system of training of civil engineers the insufficient attention is paid to development of social competences. For comparison, at other large technical universities of the world the volume of humanitarian, social and behavioral sciences makes up to 9 units against 3 in Russia [17, 18]. The lack of school hours forces authors of the training courses to use active and interactive methods of training, to include group work in all types of studies from a theoretical course before control of knowledge.

Efficiency of such pedagogical method is confirmed by results of group work. From the first to the last occupation the expressed positive dynamics in establishment of interaction between students is observed. It is determined by amount of the spent time for overcoming a contradiction, establishment of consent between participants of team and degree of the personal liability for the received general result.

It should be noted that the rate was successfully tested in 2015/2016 and 2016/2017 academic years and received positive reviews from students of the Moscow state construction university. It is confirmed by high attendance at lectures, activity of students during the carrying out business games and creation of reflexive reports [19].

\section{References}

1. Z.I. Ivanova, O.V. Yudenkova, A.D. Ishkov, E.A. Shnyrenkov, International Education Studies, 8 (5), 232 - 239 (2015)

2. M.G. Leontev, MATEC Web of Conferences, 73, 07005 (2016)

3. J. Parasonisa, A. Jodkob, Procedia Engineering, 57, 876 - 881 (2013)

4. E. Khripko, MATEC Web of Conferences, 73, 07021 (2016)

5. S. I. Ali, Procedia Engineering, 107, 11 - 17 (2015)

6. I.P. Pryadko, International Journal of Applied Engineering Research, 21, 42147-42152 (2015)

7. E.A. Shnyrenkov, I.P. Pryadko, Procedia Engineering, 117, 325-330 (2015)

8. A.Ishkov, T. Magera, Procedia Engineering, 117, 148 - 153 (2015)

9. H. S. M. Hasan, H. Ahamad, M. R. Mohamed, Procedia Engineering, 20, $291-297$ (2011)

10. O.V. Solnyshkova, E.V. Dudysheva, Education Technologies, 19, 8-13 (2016)

11. A. Bakioglu, G. Bakioglu, G. Bakioglu, Proceedings of ICDMCE'2015, 101-107 (2015)

12. G. Albayrak, I. Ozdemir, U. Albayrak, Organization, Technology and Management in Construction, 6(2), 1003-1009 (2014)

13. S. Lysov, M. Balzannikov, V. Evstropov, M. Lysov, Procedia Engineering, 117, 218 $224(2015)$

14. A. Bashkarev, Procedia Engineering, 117, 60 - 65 (2015)

15. E.A. Shnyrenkov, E.V. Romanova, Procedia Engineering, 117, 336-341 (2015)

16. A.D. Ishkov, M.G. Leontev Procedia Engineering, 117, 142-147 (2015).

17. URL: http://cce.oregonstate.edu/graduate-academics

18. Civil Engineering. SDSU General Catalog 2013-2014, 182-185 (2013)

19. A.D. Ishkov, N.G. Miloradova, SGEM-2016 Conference Proceedings, 217-223 (2016) 